\title{
HIV/AIDS morbidity/mortality, access to social support and household utilization of natural resources in Ngamiland, Botswana
}

\author{
B. N. Ngwenya ${ }^{1} \&$ O. T. Thakadu ${ }^{2}$ \\ ${ }^{1}$ University of Botswana, \\ Harry Oppenheimer Okavango Research Centre, Botswana \\ ${ }^{2}$ Agricultural Education and Communication, University of Florida, USA
}

\begin{abstract}
The dynamics of household response to AIDS impacts are complex and differ according to the severity of illness, multiplicity/frequency of death occurrences, availability and access to support structures as well as survival strategies embedded in the context of culture and biodiversity. This paper focuses on household responses to AIDS related stressors and utilization of natural resources by communities involved in Community Based Natural Resource Management (CBNRM) projects in Ngamiland, in north western Botswana. The study involved two single village and two multi-village community trusts. Data were collected through a simple random sampling of 121 households obtained from the 2001 national population census enumeration areas. The results showed that households in CBNRM villages have diverse sources of livelihoods such as farming; basket making and government assistance, sale of grass and reeds, fishing and remittances. More than half of sampled households had orphans, $68 \%$ had a continuously ill person (CIP) in the last five years, and, of these, $63 \%$ had died within the past year. Affected households received support primarily from the extended family, neighbours, church groups and friends. The study concludes that, in Ngamiland, access to external/formal and internal/informal social support mediates HIV/AIDS related morbidity and mortality, and helps households cushion the environmental impacts of AIDS by acting as a buffer against selection and over utilization of natural resources.

Keywords: HIVIAIDS, CBNRM, natural resources management, social support.
\end{abstract}




\section{Introduction}

Natural resources represent a central component of rural livelihoods. Impacts of the HIV/AIDS epidemic in Botswana society cut across natural and non-natural resource based livelihood systems. To date, the environmental dimension of HIV/AIDS morbidity (and mortality) has received limited attention. Numerous case studies have been conducted on the linkages between HIV/AIDS and natural resources management in Kenya, Namibia, South Africa [6, 8], Uganda [12], Malawi [4, 10] and elsewhere [1]. Furthermore, Hunter and Twine [7] and Erskine [5] have not only established the impact of HIV/AIDS on natural resources management, but also provide insights on how to mitigate its effects [11].

This paper builds on the few studies that assess the impacts of HIV/AIDS on natural resources utilization and access with particular reference to Community Based Natural Resource Management (CBNRM) in Botswana. CBNRM projects in the country constitute an important national strategy for combating poverty in rural communities - by creating employment - and for promoting sustainable use of natural resources [9]. In addition, CBNRM programmes offer a workable opportunity to address HIV/AIDS impacts on natural resources (water, forest, soil, wildlife, land, fisheries, veld products and conservation issues) [13]. In Botswana, HIV/AIDS prevalence varies from as low as $15 \%$ to as high as $40 \%$ in some districts [3]. National figures however; camouflage the severity of impacts on specific livelihood systems (such as CBNRM). Disaggregated data can only be obtained through systematic assessment of micro impacts in particular communities and livelihood systems, without necessarily down playing macro effects of the epidemic.

\subsection{Objectives of the study}

The overall aim of the study was to assess the prevalence of HIV/AIDS morbidity/mortality in relation to utilization of natural resources in CBNRM communities in rural Botswana. The specific objectives of the study were to:

1. Assess the prevalence of HIV/AIDS related mortality and morbidity in CBNRM areas in Ngamiland.

2. Investigate sources of support for affected households to mitigate the impacts of the disease.

3. Investigate the impacts of the disease on access to, selection and utilization of natural resources in CBNRM communities in Ngamiland.

\section{Study setting}

The study was based in Ngamiland district in the north-western part of Botswana. The Okavango Delta, a Ramsar wetland of international importance, is also located in Ngamiland. The Okavango Delta is rich in biodiversity which 
is essential to the livelihoods of populations inhabiting the area. There is a high concentration of CBNRM activities in Ngamiland: for instance, there are twentyone CBNRM community based organizations (CBOs) trusts in Ngamiland covering at least sixty-three villages in the district. Also, Ngamiland CBNRM CBOs are among the highest income generating institutions. Also, the district is home to some of the oldest CBNRM trusts in the country operated by one single joint venture partner since inception. Although rich in natural and CBNRM institutional capital capable of impacting positively on livelihoods, several factors disadvantage Ngamiland. HIV/AIDS prevalence in the district is high and there is a low concentration of both HIV/AIDS service NGOs/CBOs (to complement government programs) and poor formal HIV/AIDS service delivery infrastructure compared to the rest of the country. There is high prevalence of HIV infection, for instance, amongst the 25-49 year age group (36\% and 29\% in Ngamiland South and North respectively) [3]. This suggests that the epidemic targets the most productive age group, which contains those who are the main participants in CBNRM related economic activities. The district is ideal, therefore, for assessing household HIV/AIDS related stressors with regard to access, selection and utilization of natural resources.

Table 1: $\quad$ Villages and sampled household.

\begin{tabular}{|l|l|l|}
\hline Name of Trust & Village & No. sampled Households \\
\hline $\begin{array}{l}\text { Mababe Zokotshama Community } \\
\text { Development Trust }\end{array}$ & Mababe & 22 \\
\hline Sankuyo & & \\
\hline Okavango Community Trust & Sankuyo & 15 \\
& Seronga & 34 \\
\cline { 2 - 3 } & Gudigwa & 12 \\
\cline { 2 - 3 } & Eretsha & 7 \\
\hline \multirow{3}{*}{ Kopano Mokoro Community Trust } & Boro 2 & 12 \\
\cline { 2 - 3 } & Xaxaba & 10 \\
\cline { 2 - 3 } & Xharaxao & 9 \\
\hline Total & & $\mathbf{1 2 1}$ \\
\hline
\end{tabular}

\subsection{Sampling and data collection methods}

The study involved eight villages, two single village community trusts, namely, Sankuyo Tshwaragano Management Trust (STMT) and Mababe Zokotshama Community Development Trust (MZCDT), and two multi-village community trusts: Okavango Community Trust (OCT) and Okavango Kopano Mokoro Community Trust (OKMCT) (Table 1). A simple random sampling of $12 \%$ of households was carried out based on the 2001 national population census enumeration areas. A total of 121 households were sampled from Sankuyo (STMT), Mababe (MZCDT), Seronga, Eretsha and Gudigwa (OCT villages) and Boro 2, Xaxaba and Xharaxao (OKMCT). This was a cross-sectional survey in which data collection was through face-to-face administration of structured interviews. Household heads or mature household representatives were interviewed in situations where the de facto head was unavailable or 
incapacitated. Informal interviews were used to collect additional information about HIV/AIDS and CBNRM issues from health care officials and CBNRM/CBO project leaders/facilitators.

\section{Study findings}

\subsection{Socio-economic profile and access to HIV/AIDS information}

A total of 121 respondents from sampled households were interviewed, of these $38.8 \%$ were male, $61.2 \%$ female, over half never married $(52.9 \%)$ and $21.5 \%$ were living together, $16.5 \%$ married, $2.5 \%$ divorced and $6.6 \%$ widowed. The average age of the respondents was 42.6 years. Household size varied from $0-5$ members (45\%); 5-10 (38\%) and 10+ (16.5\%). Overall, the level of human capital development of respondents tends to be low because $43.0 \%$ have had no schooling, $25.6 \%$ had primary education, $29.8 \%$ secondary and $1.9 \%$ tertiary.

As expected, most respondents had heard about HIV/AIDS, were knowledgeable about how the disease is transmitted and could correctly identify how a person can get infected. CBNRM communities have access to HIV/AIDS information (through radio, health clinics, community meetings, and workshops). People also were conversant about what to do when ill including what to do to reduce sexual re-infection and maintaining a healthy life style.

\subsection{Primary sources of livelihoods}

Households in CBNRM communities have diverse sources of livelihood. The importance of natural resource and non-natural resource based livelihood activities in these communities tends to fall within the primary-secondary continuum. In any given seasonal/food calendar, some activities are carried out sequentially, others are done simultaneously. The sources of income in sampled villages include farming (51.2\%); cash employment from CBNRM joint partnerships (40\%); basket making and government assistance (25\%) respectively; poling, sale of grass or reeds (15\%); fishing, sale of traditional beer and receipt of remittances $(12 \%)$. However, residents of single village CBNRM communities such as Sankuyo and Mababe tend to benefit most from joint venture formal employment.

Respondents were asked to rank order sources of income. The first most important source of income was formal employment (80\%), CBNRM employment $(64.6 \%)$, farming $(54.7 \%)$, poling and sale of traditional beer, $(50 \%)$, basket making $(24 \%)$, receipt of government social welfare assistance $(16 \%)$, and thatching grass, hawking and remittances. This was followed by remittances $(77.8 \%)$, fishing (43.8), thatching grass/reeds $(37.7 \%)$, poling $(35 \%)$, basket making (32\%), farming (26.4\%) and CBNRM employment $(21.7 \%)$ respectively. The third most important sources of income were fishing $(50 \%)$, basket making (44\%), government assistance (43.3\%) and farming (18.9\%) (Table 2). 
Table 2: $\quad$ Rank ordered sources of income.

\begin{tabular}{|l|r|r|r|r|}
\hline & $\begin{array}{c}\% 1^{\text {st }} \text { Most } \\
\text { important }\end{array}$ & $\begin{array}{c}\text { \% } 2^{\text {nd }} \text { most } \\
\text { important }\end{array}$ & $\begin{array}{c}\text { \% } 3^{\text {rd }} \text { Most } \\
\text { important }\end{array}$ & \multicolumn{1}{|c|}{$\mathrm{N}$} \\
\hline Formal employment & 80 & 13.3 & 6.7 & 45 \\
\hline $\begin{array}{l}\text { Cash employment form } \\
\text { CBNRM }\end{array}$ & 64.6 & 21.7 & 8.7 & 23 \\
\hline Farming & 54.7 & 26.4 & 18.9 & 53 \\
\hline Fishing & 6.3 & 43.8 & 50.0 & 16 \\
\hline Basket making & 24.0 & 32.0 & 44.0 & 25 \\
\hline Poling & 50.0 & 35.0 & 15.0 & 20 \\
\hline Sale of crafts & - & 6.0 & 4.0 & 5 \\
\hline Sale of traditional beer & 50 & 30 & 2.0 & 10 \\
\hline Thatching grass/reeds & 12.5 & 37.5 & 5.0 & 8 \\
\hline Hawking & 12.5 & 7.5 & 12.5 & 8 \\
\hline Remittances & 11.1 & 77.8 & 11.1 & 9 \\
\hline Government assistance & 16.7 & 4.0 & 43.3 & 30 \\
\hline
\end{tabular}

\subsection{Morbidity, mortality and access to support}

\subsubsection{Orphans}

The presence of orphans has been used as proxy indicator of death of parents most likely due to AIDS. More than half of households in CBNRM communities had absorbed orphans, ranging from 1 to 6 . The incidence of orphanhood differed from one village to another due to differential HIV infection rates. In Botswana, orphans registered with the Orphan Care Desk Office (which is located in the Social and Community Development Department (S\&CD)), receive assistance. In the study area, at least $67.9 \%$ received a supplementary food basket and psychosocial support from social workers. Other sources of material and emotional support came from the extended family (64\%), neighbours $(32.7 \%)$, Trust $(26 \%)$ and social welfare groups $(12.8 \%)$. Contrary to expectation, support from extended family was rated as helpful (78\%), neighbours $(55 \%)$, followed by friends $(28.6 \%)$ and church groups $(26.3 \%)$.

\subsubsection{Morbidity, mortality and access to health services}

Approximately $68.4 \%$ of households had a continuously ill person (CIP) in the last five years. Slightly more than half of CIP patients were males. The number of CIPs in these household varied from one to numerous, for instance, $38 \%$ had one CIP, $17 \%$ two, $10 \%$ had three, $7 \%$ had four and $6 \%$ had five and above. Villages of Eretsha and Xaxaba appear to have been most affected, followed by Xharaxao and Seronga.

The majority of respondents (55\%) indicated that the CIPs were primary providers. These were farmers and trust or government employees. In Mababe, Xaxaba, Eretsha and Sankuyo, more than $80 \%$ of CIPs were primary providers who worked for Trust Joint Venture partnerships. Overall, 53.4\% CIPs were cared for less than one year, $21.6 \%$ for one year, $12.5 \%$ for two years, $5.7 \%$ for three years and $6.8 \%$ for four years and above. Several factors contributed to 
variations in length of care giving period. These included the fact that about $62.9 \%$ of patients care for died within a year, $28.1 \%$ were alive, and $9.0 \%$ died after several years. Informal interviews with family members suggested that early HIV testing, acceptance and disclosure of HIV status to a confidant, family de-stigmatization, patient access to and adherence to treatment regimes such as antiretroviral drugs (ARVs) and TB treatment were important life or death determining factors. Self-disclosure was apparent since about $38.2 \%$ of caregivers knew the HIV status of their patient. Approximately $44.8 \%$ patients were $\mathrm{HIV}+$, some were either on ARV or TB treatment or in the process of ARV enrolment.

Although the medical model seems to predominate in HIV/AIDS intervention (prevention, care and support) country wide, villagers in the study area tend to straddle modern and traditional health care systems; the difference is a matter of degree. The villages of Maun and Gumare have officially registered associations of traditional healers and they also have primary hospitals and clinics. Diversity of treatment options, implicitly or explicitly, gives affected individuals in rural settings some flexibility.

In households where there was more than one CIP over the last five years, some care givers nursed the sick people simultaneously $(17.8 \%)$ while others did so sequentially (77.8\%). Caring for one CIP after another regardless of the sequence of episodes disrupted household economic activities. Response strategies included abandoning economic activities to care for the patient $(37 \%)$, reducing labour time $(26.9 \%)$, struggling to survive one day at a time or switching to alternative activities $(6.4 \%)$. However, some respondents $(15.4 \%)$ indicated that caregiving did not affect household regular economic activities. Follow up interviews suggested that where a CIP has either been chronically unemployed, their illness and or demise had limited impact on household livelihood activities (especially where support from close family members was forthcoming). Only $1 \%$ of affected household sold some assets to cope with illness.

\subsection{Care and support}

Households affected by death or illness in CBNRM communities received care and support from a range of sources. Extended family members (64.6\%) and neighbours (37.7\%) appear to be key social actors in providing social relief to households in distress. Church groups (33.8\%) and friends (29.9\%) are also important sources in the care and support continuum. Overall, support from extended family was considered helpful, followed by church groups and neighbours. Kinds of assistance provided included emotional support (79.4\%), food provision and preparation (65.1\%), financial support $(50 \%)$, collection of water and wood $(48.2 \%)$, cleaning yard and house $(43.1 \%)$ and collection of medicine $(29.6 \%)$.

However, informal interviews suggest that many villagers maintain multiple residences. The "parallel outward" flow of the sick, dying or dead from Mababe and Sankuyo for instance, is to some extent due to "enclave" settlements in Maun or Seronga and or, for lack of a better concept, "multiple or dispersed 
residences" across villages. 'Enclave" settlements have emerged within existing Maun wards (kgotla) such as in Sedie or Botsabelo. These sub-groups own a residential plot/s, migrate seasonally or intermittently live and or do temporal or 'piece jobs' opportunistically in these localities.

It appears that Mababe and Sankuyo experienced complex "parallel outward," intra-district migration of young people. One group migrated from remote rural areas to "urban villages" such Maun, Gumare or Seronga in search of formal employment. When they became seriously ill, they are less likely to return to their home village, and if they die, they were most likely to be buried in Maun. Another group opted to stay in the village of birth and was mostly likely to be employed by safari companies in Joint Venture Partnerships. However, when they became ill, they were more likely to migrate to Maun not only to have access to better health facilities, but also to be cared for and supported by kin members living there. In both scenarios, access to kinship support networks and health care facilitates appears to stimulate and sustain outward migration flows. The strength of social and institutional ties within CBNRM communities, therefore, is an important response strategy for household under HIV/AIDS related stressors (illness or death).

\subsection{Morbidity and utilization of natural resources}

With regard to collection and use of natural resources prior to chronic illness episodes, the majority of respondents (95.9\%) indicated that they collected firewood for use, 5.5\% collected it for sale during normal period and only $3.3 \%$ indicated that they sold it as a coping mechanism during illness episode. Likewise, the majority $(84.3 \%)$ harvest grass for domestic use, $24.2 \%$ for commercial purpose and $8.3 \%$ sold during illness. Again food plants were also harvested for domestic use $(71.9 \%)$, whereas $10 \%$ for sale and $5.8 \%$ sold during illness. With regard to medicinal plants, $28 \%$ indicated that they harvested for daily consumption and only $1.7 \%$ for sale. Informal interviews revealed that wild foods plants include Berchemia discolor Bird plum (motsintsila), Grewia sp. and Brandy bush (moretlwa). Medicinal plants are harvested to treat a wide range of health conditions (coughs and colds in children, pregnancy and child birth, old age related chronic conditions and so on). Interestingly, none of the respondents claimed harvesting medicinal plants as an income generating coping mechanism during illness. Disaggregated data however, suggest that $50 \%$ and $33 \%$ of households in Xaxaba and Xharaxao respectively, sold reeds, and $44 \%$ and $42 \%$ sold grass thatching as response mechanism for social distress. Sale of food plants was evident in Gudigwa, Seronga and Xaxaba. The latter village appears to rely on harvesting natural resources, especially grass and reeds, for both subsistence and commercial purposes, and also during normal and distressed periods.

\section{Discussion}

Compared to other districts in the eastern part of the country, human capital development (as measured by level of educational attainment) in Ngamiland is 
low. It is thus not surprising that a significant proportion of respondents have no formal schooling. Chronic illness and mortality further erode the human capital base of affected households. Inevitably, death changes household composition, for instance, by increasing the number of orphaned children, reducing access to or re-allocation of experienced labour in production sectors such as CBNRM, farming, cash employment and other income generating activities. Paradoxically, death can also bring psychosocial relief in that the event free caregivers to switch from 'invisible,' uncounted non-market caregiving activities to 'visible,' quantifiable market undertakings.

Also, absorbing orphans reconfigures household composition. This can have both positive and negative effects on household human and financial capital. On the negative side, if the orphan is young and requires care, extra labour demands are placed on the caregivers. However, access to support from extended family and or neighbours helps orphan-recipient households to cushion negative effects. On the positive side, absorption of older orphans could mean provision of extra labour, direct financial and material welfare benefits from government or donor agencies. Clearly receipt of remittances and government assistance, are the most important for $11 \%$ and $16 \%$ of households in the study area. A welfare benefit, such as a social pension, facilitates labour migration and female pension recipients in the household reduce the probability of a male leaving the household and have the opposite effect on women's migration [2]. More research is needed to establish, for example, the link, if any, between social welfare programs 'parallel outward' migrations from CBNRM communities to 'enclave' settlement in 'urban villages.'

Although respondents admit to consulting various health care systems in the village for various ailments, they are, however, quick to point out that AIDS related conditions are better handled in clinics or hospitals. Access to health systems (modern and traditional) also contributes towards minimizing the impacts of HIV/AIDS on utilization of natural resources as first line of defence.

The strength of, and access to, kin and non-kin based social relationships (or social capital) matters in CBNRM villages. Sources of material and psychosocial/emotional support networks include those from formal (from government and NGOs/CBOs) and informal (extended family, neighbours and remittances). The forms of support flowing from these include gifts, childcare, home visitation and labour sharing arrangements especially by close family members and neighbours. Affected households in all villages in the study appear to have very strong social support structures to draw upon during times of distress, especially from extended family and neighbours. Variations are expected of course, with some households having more support (and therefore less vulnerable to negative effects of AIDS related mortality and morbidity) and others, less. Although seemingly mundane, these are critical elements that mediate response strategies of households under distress particularly with regard to utilization of natural resources in the Okavango Delta.

Access to financial capital (cash income) through sustained cash employment helps reduce household vulnerability to negative impacts of the disease. Also, CBNRM villages in the Okavango Delta have an abundance of natural capital 
(forest, reeds, grass, water, land, and fish) that is largely utilized for domestic purposes and for commercial purposes on a limited scale. Furthermore, few households sold veld products specifically as a distress response strategy, especially in Seronga and Gudigwa. Xaxaba village is inside the Delta and most residents work for safari camps, but the majority originates from Seronga, where access to waterway transport makes the village a potentially good market for reed/grass. Residents of Xharaxao and Boro 2 are also a stone's throw away from Maun, a likely market for thatching grass (for domestic and business purposes).

\subsection{Conclusion}

Response strategies of AIDS affected households in Ngamiland can be better understood in relation to access and utilization of natural and non-natural based resources or 'assets' available to a household as well as the enabling social and institutional relations. AIDS related morbidity may induce changes that are likely to shape household access, collection, utilization and conservation of key natural resources in their locality. The study has shown that social support structures and kinship networks mediate HIV/AIDS related stressors such as chronic illness and death and potentially act as a buffer against AIDS affected households from adopting response mechanisms that could have 'erosive' effects on natural resource access and utilization. Joint venture partnerships in CBNRM communities not only create employment opportunities, but also implicitly prevent the collapse of social support systems, for instance by providing transport for the ill, dying or dead, and social welfare provision to orphans and the elderly. Demonstrated extended family support and good "neighbourliness" in the study areas should be interpreted in the broader context of enabling social and institutional relations.

\section{References}

[1] AIDS Brief. CBNRM Brief for Sectoral Planners and Managers. Development Alternatives, USAID. http://www.frameweb.org/

[2] Barrientos, A. Non-contributory Pensions and Poverty Reduction in Brazil and South Africa, Department of International Development, University of Manchester. http://www/ds.ac.uk/ids/pvt/pdf-files/non-contributory_ pensions.pdf

[3] Central Statistics Office (CSO). Botswana AIDS Impact Survey (BAIS II), Ministry of Finance and Development Planning. Gaborone, 2004

[4] COMPASS. Impacts of HIV/AIDS on Natural Resource Management in Malawi. Document 55. Blantyre, 2003

[5] Erskine, S. Red Ribbons and Green Issues: Exploring HIV/AIDS as an Environmental Concern. Health Economics and HIV/AIDS Research Division (HEARD). University of KwaZulu-Natal, http://www.hivan.org.za/admin/documents/Red\%20Ribbons\%20and\%20 Green\%20Issues.doc. 
[6] Freeman, P. H. CBNRM and AIDS in Bushbuckridge, Northern Province. South Africa. An Exploratory Geographic Analysis. South Africa, http://www.popline.org/doc/1564/174389.html

[7] Hunter, L., \& Twine, W. Adult Mortality, Natural Resources and Food Security: Evidence from the Agincourt field site in rural South Africa. Centre for African Ecology, University of Witwatersrand, South Africa, 2005

[8] Johnson, T. Challenges and Responses to Impacts of HIV/AIDS on CBNRM in a Trans-boundary Context. South Africa. 2002.

[9] Kgathi, D. L. \& Ngwenya, B. N. Community Based Natural Resource Management and Social Sustainability in Botswana: Implications for Natural Resource Management Botswana: Botswana Notes and Record (Special Edition) 37, pp61-79. 2005

[10] Mauambeta, D. D. C. HIV/AIDS Mainstreaming in Conservation: The Case of Wildlife and Environmental Society of Malawi. http://www.rmportal.net/library/hh_main/hh_hivaids/HiVandConservation -Mainstreaming.pdf/?searchterm=- participatory\%20planning.

[11] Oglethorpe, J., Gelman, N. HIV/AIDS and Conservation. Impacts and ways to reduce them. Fact sheet for the Conservation Community. http://www.frameweb.org/

[12] Ruhweza, A. Exploring the Relationship Between HIV/AIDS and Community Based Natural Resource Management (CBNRM). Uganda. 2001

http://www.gbf.ch/ab_received.asp?no=37\&lg=EN\&app=\&now=2\#2

[13] USAID. Bureau for Africa, Office of Sustainable Development. AIDS Briefs for Sectoral Planners and Managers: Community Based Natural Resource $\quad$ Management. 2005. http://www.afrsd.org/Environment/AIDS\%20Brief-all-150\%20res.pdf 